\title{
Editorial
}

\section{On Idiopathic Afflictions}

\author{
Daniel J. Schneck \\ Virginia Polytechnic Institute and State University, Blacksburg, Virginia, USA
}

Address correspondence to Daniel J. Schneck, adanielj@vt.edu

Received 10 September 2010; Accepted 10 September 2010

The Russian philosopher, George Ivanovich Gurdjieff (1866-1949), once declared that people are always offering opinions about things about which they know absolutely nothing (or at best, very little). In our nation's court-rooms, many of us routinely deal with glaring examples of this observation - examples that often involve "expert" witnesses giving testimony about alleged "workrelated-musculoskeletal-disorders" (WMSD's), especially idiopathic ones!

By definition, an idiopathic affliction is one for which a cause is unknown. The word idiopathic derives from the Greek idio- which means "distinct, recognizable," attached to pathos, which is Greek for "suffering, pertaining to disease," hence, idiopathic, "a state of suffering (-pathic) lacking a distinct (idio-) origin; a disease (-pathic) without a recognizable (idio-) cause; an affliction arising spontaneously or from an obscure set of determining factors." Included in this category are such afflictions as carpal tunnel syndrome, plantar fasciitis, certain degenerative joint diseases (such as osteoarthritis), certain spinal disc bulges (which may or may not eventually rupture), and others.

That having been said, it never ceases to amaze me at how, despite there being no known cause for these and other musculoskeletal afflictions, health care providers routinely testify, under oath, as to (1) the actual cause(s) of such afflictions and (2) their "obvious work-relatedness." As I listen to or read about such testimony I cannot help but wonder why these folks are not in Sweden, collecting their Nobel Prize in Medicine for having found the cause of these idiopathic afflictions, rather than here, testifying in court.

Now, I will admit that there is a vast literature "out there," few of it peer-reviewed, that attempts to attach workrelated causes to many of these WMSD's. But, as Gurdjieff observed: the vast majority of these publications offer unsubstantiated, conjectural opinions, and it is relatively easy to verify that they opine about things they know little or nothing, at least not in a rigorous, scientific sense. Moreover, as is true for any affliction for which there is no known cause, everybody has a "theory." Thus, it is not unusual to find ... for every article that attaches a positive correlation to the work-relatedness of the said affliction another one that vehemently denies such a correlation! In either case, the authors just do not know, and so one finds them using speculative words like "It is plausible to surmise that ...," "Might be associated with ...," "Appears to be correlated with ...," "May derive from ...," and so on all conjectural phrases, often based on statistical inference, which, frankly, can be used to "prove" just about anything when there is a laundry list of confounding variables involved!

You might justifiably ask: "So, Dr. Schneck, when called upon to offer expert testimony, are you guilty of offering opinions that go beyond your level of knowledge and understanding of the issues involved?" As being human, and thus not perfect, I would have to say that I am not entirely innocent of this charge. However, I do know what I know, and I at least make every effort to limit my testimony to that range of knowledge. I try not to extrapolate beyond the limits of the state of the art; I endeavor to keep things in the proper perspective, and I am honest with myself and with my colleagues. I will never testify to something I do not sincerely believe to be true and scientifically justifiable. So, I challenge all of you to turn inward and ask yourself, being totally honest, "Is Gurdjieff correct? To what extent do $\underline{I}$ frequently offer opinions about things I really know nothing about?"

Dr. Daniel J. Schneck Editor-in-Chief 